\title{
Demand for Public Events in the COVID-19 Pandemic: A Case Study of European Football
}

\author{
by J. James Reade and Carl Singleton
}

Discussion Paper No. 2020-09

Department of Economics University of Reading Whiteknights

Reading

RG6 6AA

United Kingdom

www.reading.ac.uk 


\title{
Demand for Public Events in the COVID-19 Pandemic: A Case Study of European Football
}

\author{
J. James Reade \\ Carl Singleton* \\ University of Reading \\ University of Reading \\ October 2020 \\ Forthcoming at European Sport Management Quarterly
}

\begin{abstract}
This study uses data from elite-level European football matches and panel data methods to suggest how people responded to the initial COVID-19 outbreak. In Italy, England and Germany, stadium attendances were negatively affected by the previous day's newly confirmed domestic cases or deaths. In France and Spain, there was no significant attendance response to the early stages of the domestic outbreaks. In all five countries, there was no negative attendance response to the number of worldwide cases or deaths as the outbreak developed. Overall, these results confirm that COVID-19 was affecting football match spectator demand before European countries enforced lockdowns and other restrictions to suppress the spread of the disease. This suggests that fans significantly responded to the risk of catching the virus. If this risk remains when stadiums reopen, then sports organisations should expect reduced ticket demand.
\end{abstract}

Keywords: Demand for sport, Stadium attendance, Coronavirus, European economy, Public health

JEL codes: I10, L83, Z20

* j.j.reade@ reading.ac.uk \& c.a.singleton@ reading.ac.uk, Department of Economics, University of Reading, Whiteknights Campus, RG6 6UA, UK. We would like to thank Antonio Cabrales, Marina Della Giusta, Brad Humphreys, Daniel Parnell, Rachel Scarfe, Daniel Schaefer, Dominik Schreyer and Paul Telemo for helpful comments, as well as participants in the Reading Online Sport Economics Seminars in March 2020. 


\section{Introduction}

On $11^{\text {th }}$ March 2020, the World Health Organisation declared that the COVID-19 novel coronavirus had become a global pandemic. Over five months later (28th August 2020), health systems in numerous countries were still being overwhelmed by the impact of the outbreak and over 830,000 people had lost their lives to the virus. ${ }^{1}$ Many countries experienced exceptionally sudden and deep economic recessions due to the measures taken to suppress or mitigate the pandemic. $^{2}$

The focus here is on the early outbreak period of the virus in Europe, specifically in England, France, Germany, Italy and Spain, up to the first full weekend of March 2020. The analysis looks at stadium attendance data from elite-level association football matches, which is the most popular sport in the world. ${ }^{3}$ In the midst of a global pandemic this severe, a focus on sport may seem trivial, or even in poor taste. However, the demand for attending sports events in these countries may tell us something about how populations respond to a public health emergency, especially one which requires social distancing, under different policy regimes. There is also little doubt that sport, in particular football, forms a central part of the social fabric of the European regions most affected so far (Giulianotti, 2012). Indeed, Bergamo, the probable epicentre of the European coronavirus outbreak (Verdoni et al., 2020) and with the highest rate of COVID-19 deaths in Italy (Reuters, 2020), is home to Atalanta B.C., who this year reached for the first time in their history the quarter finals of the premier European competition, the UEFA Champions League, even as the outbreak took hold. ${ }^{4}$ During both World Wars, regional football continued in Europe, a testament to its social and political importance in troubled times (Benoit, 2008; Woolridge, 2002). But from the second weekend in March 2020, European professional sport, including football, was largely in shutdown until mid-May, when some competitions resumed, though with mostly empty stadiums.

This paper relates to two principal strands of literature. First, it contributes microeconomic evidence on the impacts of a pandemic or a public health emergency (e.g., Keogh-Brown et al., 2010, for a macroeconomic analysis, or Kuo et al., 2009; Page et al., 2012; Rassy \& Smith, 2013, for studies focused on the tourism sector). Second, there is a vast literature analysing

\footnotetext{
${ }^{1}$ Source: COVID-19 Dashboard by the Center for Systems Science and Engineering (CSSE) at Johns Hopkins University; https://coronavirus.jhu.edu/map.html

${ }^{2}$ See for example the IMF World Economic Outlook, April 2020; https://www.imf.org/en/Publications/WEO/Issues/2020/04/14/weo-april-2020.

${ }^{3}$ For example, see the Nielsen World Football Report, 2018; https://www.nielsen.com/uk/en/insights/report/2018/world-football-report/.

${ }^{4}$ Indeed, it has been suggested that a match between Atalanta B.C. and Valencia CF on $19^{\text {th }}$ February 2020 was ground zero for the spread of the virus in Spain as well as in Italy; see https://rep.repubblica.it/pwa/generale/2020/03/20/news.
} 
and modelling the demand for professional sports and specifically football stadium attendances (e.g., for England see Bird, 1982; Buraimo, 2008; Feehan et al., 2003; Forrest \& Simmons, 2002; Simmons, 1996; Simmons \& Forrest, 2006, for France see Andreff \& Scelles, 2015, for Germany see Pawlowski \& Anders, 2012, for Italy see Bond \& Addesa, 2020, for Spain see Garcia \& Rodríguez, 2002, for evidence outside of the top European leagues see Buraimo et al., 2018, and for women's football see Valenti et al., 2020), but little on the effects of shocks like COVID-19, with two exceptions. Gitter (2017) studied Mexican baseball attendance during the H1N1 'Swine flu' outbreak, finding reductions in game attendances of 15-30\%. Reade et al. (2020) studied Belarussian Premier League football attendances after COVID-19, i.e., in one of the few countries where football was not shut down after the virus outbreak. In this quite particular context, Reade et al. (2020) found that demand decreased significantly during the initial period of maximum uncertainty about the impacts and risks of Covid-19, in March and April 2020, but then recovered in the following months, even as the numbers of reported cases and deaths increased.

The rest of the paper proceeds as follows: the next section describes the data on football match attendances and the COVID-19 outbreak; this is followed by the estimation strategy to assess the impact of the European COVID-19 outbreak on implied spectator demand; the next section presents the results; the penultimate section discusses the implications of these results in the context of the ongoing COVID-19 pandemic, focusing on European professional football; and the final section offers some concluding remarks, as well as identifying areas for further research.

\section{Data}

A dataset of match attendances and results was constructed from www.worldfootball.net for the big five European football leagues, i.e., the English, Italian, French, Spanish and German top leagues. In addition, the entire history of European domestic and continental professional football result outcomes was used to construct the Elo ratings of teams, as measures of their time-varying strengths. ${ }^{5}$ These measures also capture the recent form of teams, as the recursive updating of the ratings after each match means that those completed more recently have greater weight, i.e., constant gain updating. Alternative measures of time-varying team strengths would include UEFA coefficients, league positions and other metrics of recent form. We prefer Elo ratings as they take into account form over different competitions, being functions of who beat who and when, throughout the history of association football, regardless of the match

\footnotetext{
${ }^{5}$ Elo ratings, originally proposed by Elo (1978) for chess players, are commonly used to estimate the relative strengths of football teams, both in practical applications (e.g., https://www.eloratings.net/) and in academic research (e.g., Hvattum \& Arntzen, 2010). See either of these sources for the mathematical details.
} 
formats. The ratings will be useful control variables in the regression model, described in the next section. For the analysis, however, the focus is on relatively recent data, from the beginning of the 2015/16 season to the COVID-19 induced football shutdown in March 2020.

The dataset used is summarised in Table 1. In each of the five top leagues over this period, it represents between 24 and 29 teams, which translate into between 496 and 709 distinct fixtures (or matchups) of specific home and away teams. The number of matches covered varies from 1,447 in France to 1,808 in England. All matches that were played behind closed doors are excluded, i.e., in approximately empty stadiums, for whatever reason, including a few occurring toward the end of the sample period due to COVID-19, mostly in Italy. Spectators were not allowed to attend theses games so it would not make any sense to include them in the analysis. Over the studied period, there was substantial variation in attendances in all five of the countries. Germany and England had the highest attendances on average, and these were also the two countries where matches were more likely to sell out in advance, with an implied excess demand (Cox, 2018). The variance of match attendances is highest in Spain. Stadium capacities rarely bind in Spain, Italy or French domestic football over this period.

Information on the numbers of daily confirmed cases from COVID-19 and related deaths was collected from 'Our World in Data' (ourworldindata.org/coronavirus-source-data). Figure 1 summarises these data, showing the pace of the outbreak in the five major European countries studied here and worldwide. These numbers relate to what had been recorded and published by midnight before the day listed. Hence they were public information by the time football matches kicked off on that same day, as well as being the most recent major news on the state of the outbreak available to spectators before they decided whether to go to a match.

\section{Estimation}

The relationship between the COVID-19 outbreak and football match attendances is estimated using a two-step strategy, applied individually to each country. This two-step approach is chosen to produce the most conservative standard errors, given that the COVID-19 information does not vary over the matches played in a country on the same day (see Donald \& Lang, 2007 or Angrist \& Pischke, 2009). It is also transparent with an unbalanced longitudinal dataset; home-team-away-team pairs, i.e., fixtures, occur infrequently and on different match days throughout the period. Variation over time in adjusted match day average attendances is used to identify the outbreak's impacts on implied spectator demand. 
In the first step, the following model is separately estimated for each country using least squares:

$$
\ln \left(\text { Attendance }_{i t}\right)=\alpha_{i}+\phi_{H(i t)}+\beta_{1} \text { HomeElo }_{i t}+\beta_{2} \text { AwayElo }_{i t}+d_{t}+\varepsilon_{i t}
$$

where $i$ denotes the identity of the home and away team pair, i.e., Real Madrid C.F. playing at home against FC Barcelona, and $t$ is the match day. Regressing the natural logarithm of the attendance in matches (1000s) on fixed effects for the identity of the fixture, $\alpha_{i}$, addresses both the different typical stadium attendances of home teams, but also that some matchups generally attract more fans, such as when local rivals play one another. It is also possible that a home team has higher or lower attendances from one season to the next, perhaps because it is playing in a different stadium or has become more or less popular. Home-team-season fixed effects are included in Equation (1) to address this, $\phi_{H(i t)}$, where $h=H(i t)$ indicates the particular home team season. These two sets of effects may also partially address the role of the competitive intensity of matches (Kringstad \& Gerrard, 2004, 2005), which has been shown to affect stadium attendance demand (e.g., Andreff \& Scelles, 2015; Bond \& Addesa, 2020; Valenti et al., 2020). The regression model also includes controls for the time-varying Elo ratings of the home and away teams, with corresponding coefficients $\beta_{1}$ and $\beta_{2}$. Fans are likely to prefer watching their teams within any given season when they are doing well, either at home or away. $d_{t}$ are match-day fixed effects, which provide measures of the average daily attendance at elite-level football in each country, adjusting for the nature of the matches that took place on the day through the fixture and home-team-season fixed effects, and the Elo ratings. The remaining heterogeneity in attendances is in the residual term, $\varepsilon_{i t}$.

In the second step, the point estimates of $d_{t}$ from the first step are used to estimate the following using least squares:

$$
\Delta \widehat{d_{t}}=\gamma+\lambda_{1} \text { NewDomestic } \text { }_{t}+\lambda_{2} \text { NewWorldwide }{ }_{t}+\phi^{\prime} \mathbf{D}_{t}+\zeta_{t}
$$

where $\Delta \widehat{d_{t}}$ gives the day-to-day change in the adjusted average log attendance within a country. The coefficients $\lambda_{1}$ and $\lambda_{2}$ provide estimates of the log point change (approximate percentage change or semi-elasticity) in stadium attendances due to the additional daily domestic and worldwide confirmed cases (or deaths) of COVID-19, announced by midnight on the day prior to a match taking place. Day of the week fixed effects are added to the model in $\mathbf{D}_{t}$, to account for the general pattern of match-day attendances from, for example, Saturday to Sunday (see Goller \& Krumer, 2020 for a description of how spectator demand for football varies throughout the week and how this can matter for match outcomes). 
To adjust the average daily attendances, the estimation period chosen for the first step is the beginning of the 2015/16 season to the last matches played with spectators before the outbreak-induced shutdown in each country, at the beginning of March 2020. Importantly, this was before any major suppression measures were implemented by the national governments. The last rounds of league matches with spectators in all five countries were played before the nationwide lockdown in Italy on $10^{\text {th }}$ March. Home and away team pairs that only appeared once in the sample period are excluded from the first step (e.g., all of Sheffield United's fixtures in the English Premier League are excluded, as they were promoted in 2019 and had not played in the previous four seasons of the top league). In the second step, only the match-day fixed effect point estimates from the beginning of the 2019/20 season in August are used, i.e., $\widehat{d_{t}} \geq 1$ Aug2020, to cover the period of the global outbreak and to address the general pattern of attendances over weekdays. It is preferable to estimate the second step in first differences, with the daily change on the left-hand side and the number of new confirmed cases (deaths) over the previous day on the right-hand side, to address potentially spurious estimates if the time series are integrated. Exploiting this day-to-day variation in match-day attendances and the COVID-19 outbreak, while being more robust, reduces the sample size in the second step to just 42-49 consecutive two-day periods in each of the five countries. The second step is estimated using ordinary least squares as there is no significant evidence of heteroskedasticity. ${ }^{6}$

\section{Results}

Figure 2 displays for each country the point estimates of the adjusted average daily match attendances from the first-step regressions of Equation (1), $\widehat{d}_{t}$, shown from January 2020. In the top-left, there appears to be no downward trend in match-day attendances in England after the first domestic COVID-19 case was confirmed in late January. There was a sharp drop in attendances on Saturday $15^{\text {th }}$ February, but at this point there were only 9 confirmed cases in the UK, though this was only a few days after the World Health Organisation had officially named the virus. There was another marked drop in match-day attendances between $7^{\text {th }}$ and $9^{\text {th }}$ March, during the final round of fixtures played before lockdown was imposed. This was just after the first COVID-19 death was confirmed in the UK on $6^{\text {th }}$ March, with two further deaths on $8^{\text {th }}$ March. The patterns in France since January were more mixed, with more variance in the adjusted match-day attendances than in England. However, there appears to have been a slight downward trend in attendances from the middle of February to the end of the last match played in March. Germany also displays a lot of day-to-day variation, with no discernible trend

\footnotetext{
${ }^{6}$ A modified Breusch-Pagan test, where the squared residuals from the second step, Equation (2), are regressed on the inverse of the number of matches per match day, returns non-significant coefficient estimates for all countries ( $p$-value $>0.1$ ). Regardless, when estimated using weighted least squares, with the number of matches per match day as weights, all our main results are qualitatively unchanged (results available on request).
} 
over the period of the outbreak, although there was a sharp drop in adjusted attendances on the final match day with fans present on $8^{\text {th }}$ March. Italy also saw a substantial drop in adjusted attendances on its final match day in this period. There is a prevalent positive match-day spike in Figure 2 for Italy on $5^{\text {th }}$ February. This was an outlier due to an unusually well-attended midweek game between SS Lazio and Hellas Verona F.C., possibly due to the home team being in Serie A title convention, with the potential of moving into second position and just two points behind the leaders with a win. However, it does not affect our second-step regression model estimates as there were no matches in Italy on either the day before or after. Finally, there is some suggestion of a downward trend in adjusted stadium attendances in Spain throughout February, but nothing else is especially distinctive in the bottom panel of Figure 2.

Going further than a descriptive analysis of patterns in adjusted match-day attendances, Table 2 shows in separate columns the second-step estimation results of Equation (2) for each of the five countries, beginning with confirmed new domestic and worldwide COVID-19 cases as the explanatory variables. In Italy (column IV), where the virus outbreak was initially more severe, attendances reduced by $13 \log$ points $(14 \%$; $p$-value $<0.01)$ for each additional 100 domestic cases announced the day before. In England and Germany (columns I \& III), attendances also had a negative $4 \log$ point $(5 \%$; $p$-value $<0.05)$ and $11 \log$ point $(11 \%$; $p$-value $<0.01)$ response to 100 new domestic cases, respectively. The equivalent responses in France and Spain were insignificant from zero (columns II \& V). The lack of a response to the initial stages of the outbreak in these countries is somewhat puzzling. It is plausible, though impossible to confirm, that Spanish and French football fans responded to the domestic outbreak by anticipating that matches would soon be played behind closed doors, as was happening in Italy by the final round of league matches in those countries. As Figure 1 shows, these two countries were closer behind Italy than England and Germany in terms of how the outbreak was progressing. Only in France was there a statistically significant response to the number of new worldwide cases being confirmed on the previous day, with an attendance increase of $4 \log$ points $(4 \% ; p$-value $<0.05)$ for every additional 1,000 cases, partially offsetting the negative but insignificant effect of domestic cases. This stand-out result is hard to reconcile with any theory of risk-taking behaviour, and may be driven by something coincidental in the nature of the matches occurring toward the end of the sample period in France, which the first-step regression model did not account for. One potential explanation is that the competitive intensity of Ligue 1 at this time was driving increased spectator demand. By the time the French 2019/20 season was cancelled in March due to Covid-19, the nine teams in positions 5-13 were separated by just four points, with only ten rounds of matches remaining. This explanation would be consistent with Scelles et al. (2016), who found that French stadium 
attendances are particularly sensitive to the potential prize of qualifying for the UEFA Europa League in positions $4-6 .^{7}$

Table 3 shows an equivalent set of results to Table 2, using the numbers of COVID-19 related deaths on the previous day instead of confirmed cases as the explanatory variable in Equation (2). Again, only in France (column II) was there a significant match-day attendance response to the number of new worldwide deaths from the virus announced on the previous day. Germany had not experienced any domestic deaths from the virus by the last football match with spectators. The numbers of daily deaths from the virus were small and not yet consistent in England, France and Spain by the time their football seasons were halted, and there was no significant effects of these small numbers on stadium attendances in these two countries. In Italy (column IV), an additional domestic death confirmed the day before was associated with a substantial and significant $5 \log$ point $(p$-value $<0.01)$ reduction in match-day attendances. In England and Germany, stadiums frequently sell out, implying excess demand. This makes it difficult to infer the true extent of the implied overall demand response to the COVID-19 outbreak from the estimates here. But sell outs are rare in Italy. Therefore, it is more reasonable to view the estimates from Serie A as capturing something of the true extent to which fans were deterred from going to the stadiums by negative news about the domestic virus outbreak.

As a caveat, if some of the attendance data used here reflect the number of tickets sold for matches rather than the seats actually filled on the day, which is likely, then the estimated responses to the outbreak here could be upper bounds. ${ }^{8}$ In other words, it is plausible that fans could have increasingly chosen not to use their advance purchased tickets during the outbreak, including season tickets, and that is not captured here. For example, the estimated negative attendance response in Germany from 100 new domestic cases was $11 \log$ points (Table 2, column III). However, Schreyer et al. (2019) described how up to one in ten tickets sold in the German Bundesliga went unused in recent seasons. Further, fans in this league responded to the perceived increased risk to their safety after the major terrorist attack in Paris on $13^{\text {th }}$ November, 2015, with increased no-show behaviour in the following weeks (Frevel \& Schreyer, 2020). The German attendance data used here are more likely to reflect tickets sold rather than actual attendances than for the other countries. ${ }^{9}$ This suggests that there could have been a

\footnotetext{
${ }^{7}$ Teams only qualify for the UEFA Europa League by finishing in positions 5 and 6 if the winners of the two domestic cup competitions finished in the top four positions. There was a high likelihood in February and March of the 2019/20 season, that the dominant league leaders Paris Saint Germain F.C. would go on to win the two domestic cup competitions, which subsequently happened.

${ }^{8}$ The over-reporting of football stadium attendances has been widely in the media. (e.g., Ian Thomson in the Guardian, September 2017, "Football clubs should stop exaggerating their attendance figures"; https://www.theguardian.com/football/2017/sep/28/football-clubs-leagues-attendance-figures-arsenal-celtic-mls).

${ }^{9}$ The data used here from Germany frequently report round attendance numbers that reflect stadium capacities, such as 75,000 for Bayern Munich in practically every home game, and this tendency is more frequent than in the data from other countries.
} 
more significant spectator demand response in Germany to the COVID-19 outbreak if it were possible to account fully for the numbers of people attending matches rather than the numbers of tickets sold.

\section{Policy implications}

The focus of this study has been on the impacts of COVID-19 on spectator demand for football. But the reality is that the reverse relationship is equally pertinent: what impact does professional football and live spectator sport have on the spread of the virus? Social distancing measures saw the end of fans in many stadiums in Western Europe from March 2020, as the pandemic was brought under control. There is some historical evidence that major sports events can have significant public health impacts. There is indicative evidence of heightened influenza infection rates from the 2002 Winter Olympics (Gundlapalli et al., 2006) and the 2006 FIFA World Cup (Schenkel et al., 2006). Even more convincing evidence was found by studying the annual National Football League Super Bowl. Using a differences-in-differences approach, Stoecker et al. (2016) found that cities in the United States which were represented in the Super Bowl had an $18 \%$ increase in influenza deaths. Nonetheless, part of understanding when to allow fans back into sports stadiums is knowing how far demand will be reduced by any ongoing risk of infection. In other words, if fans were allowed back tomorrow, will few enough actually turn up and congregate such that social distancing in the stadium, concourses and surroundings is practical?

The results here cast a shadow over the possibility that spectator sport will rebound even when social distancing measures are eased by governments. One argument is that there will be a pent-up demand effect, that could offset or even override the negative effects from any ongoing risk of COVID-19 infection. Two of the most sustained attendance increases in the history of English football came after the suspensions brought about by each World War (e.g., Dobson \& Goddard, 1995). But this is a tentative parallel at best, as the results here show that in the initial stages of the European COVID-19 outbreak there were already substantial negative demand responses, suggestively because of the implied risk of infection, even when the significance of the disease and its implications were both being played down by politicians. ${ }^{10}$

\footnotetext{
${ }^{10}$ For example, the UK Prime Minister boasted of continuing to shake hands on $3^{\text {rd }}$ March 2020 and was observed doing so on $9^{\text {th }}$ March 2020; see The Guardian, $5^{\text {th }}$ May 2020:

https://www.theguardian.com/politics/2020/may/05/boris-johnson-boasted-of-shaking-hands-on-day-sage-warned-not-to
} 
The elite European football clubs represented in this study are likely to survive the outbreak financially, given their access to substantial funds besides match-day gate receipts. ${ }^{11}$ But professional football below that level still largely relies on getting the fans in on match days. By forensically studying the 2018/19 accounts of professional football clubs in England and Wales, Szymanski (2020) has found that the majority of these firms were already on the verge of insolvency before the loss of revenues and write-down of assets, i.e., player valuations, due to COVID-19. ${ }^{12}$ Our results here imply that clubs will likely face substantial ongoing losses even after they can fully re-open their stadiums, since spectator demand will be decreased so long as there is a continued risk of becoming infected at matches.

Given the suggested reluctance of fans to return to football stadiums when social distancing measures are relaxed, clubs may have to become especially flexible and agile with dynamic ticket pricing to begin with, until they understand how their customer base has altered, learning from the studies of when this has been applied by sports organisations in the past (e.g., Shapiro \& Drayer, 2012, 2014, and specifically for football, Kemper \& Breuer, 2016. See also Soebbing, 2019, for a survey on the economics of sports ticket pricing). Kemper \& Breuer (2016) showed that ticket prices for home fixtures at Derby County F.C., a team in the second tier of English football, systematically increased over time from a base starting price as the stadium filled up to a matchday. This suggests that football fans are myopic. With potentially restricted stadium capacities when crowds are allowed back into stadiums post COVID-19, clubs could look to exploit the tendency of their fans to buy tickets late by significantly increasing prices in the days leading up to matches.

In a world with social distancing and people who are concerned about the risks of catching or passing on COVID-19, teams could also look toward group 'friends and family' ticketing. If the restrictions imposed by authorities involve minimum distances between numbers of households in public spaces, then group price discounts may increase revenue by filling a greater proportion of seats. We found little evidence on the extent to which elite football clubs already apply family discounts, but Clowes \& Clements (2003) found that they were rare over two decades ago in the English Premier League, suggesting that clubs saw little added value in them. COVID-19 may change this.

With reduced capacities, some clubs will have to decide who among their supporters should be offered seats first. For two reasons, it is clear that they should prefer longstanding season

\footnotetext{
${ }^{11}$ See the Deloitte Football Money League 2020 report for estimates of the dependence of top European football clubs on gate receipts and related revenues; https://www2.deloitte.com/bg/en/pages/finance/articles/football-money-league-2020.html

${ }^{12}$ This research was presented at the Reading Online Sport Economics Seminars (ROSES) on 17 April 2020. See here for a public recording:

https://www.youtube.com/watch?time_continue=4006\&v=viPqe93rW2c\&feature=emb_logo
} 
ticket holders. First, clubs should want to protect the loyalty of these customers (see Schreyer et al., 2018, for evidence on the determinants of stadium attendance by season ticket holders). Second, these supporters are likely to have higher willingness to pay (e.g., Simmons, 1996), and thus clubs could generate greater revenues from this group.

Besides matchday ticketing strategies, clubs may have to find more innovative ways of raising revenue with their stadiums. For example, one particularly innovative club in England has erected a screen on its pitch to show new and classic films as a drive-in cinema - though the groundsman was probably not too pleased about it. ${ }^{13}$

It is likely that if the present structures of professional football are to survive, then some degree of consolidation will be required in response to the crisis caused by COVID-19. Szymanski (2020) notes that this is particularly the case since much of football club debt is owed to other clubs. He suggests that consolidation should involve assigning all future broadcast rights to a collective fund, from which those unable to collect unpaid debts can make claims, including delayed transfer fees and player wages. In other words, the only way to save the professional football pyramid today is to leverage the future value of football after COVID-19.

\section{Concluding remarks}

This paper provides an analysis of the initial impact of COVID-19 on the demand for attending elite-level football matches. There were negative impacts on revealed spectator demand in Italy, England and Germany during the initial outbreak in Europe, though only in response to the domestic outbreaks rather than the emerging worldwide picture. In France and Spain, there was no statistically significant response to the respective domestic outbreaks. There were significant positive effects of global cases and deaths in France, though we speculate that this was driven by the coincident demand effects of how competitive the Ligue 1 season was in February and March 2020.

Turning to future research, the nature of the reporting of the virus, and of football, affords a more thorough regional demand and response analysis to the outbreak, that may even guide policy makers in managing suppression measures going forward. But applying these results too far beyond the initial outbreak period would be speculative because, if nothing else, a pent-up demand effect might be expected once football matches and other public events resume. It would also be interesting to compare results from football to other frequent and major sports events in Europe over the same period, such as basketball games. A similar analysis of

\footnotetext{
${ }^{13}$ BBC Sport, 22 ${ }^{\text {nd }}$ May 2020: https://www.bbc.co.uk/sport/football/52680375
} 
the H1N1 'Swine Flu' outbreak of 2009 in Europe may also demonstrate how general these responses are, though that outbreak was substantially less lethal. Finally, more detailed data might allow a comparison of whether these patterns are driven by season-ticket holder no shows or more casual fans staying away from the stadiums, with potentially different management implications in either case. Though such data are difficult to come by, recent studies of German professional football have shown that making such a distinction can reveal novel patterns in fan behaviour (Schreyer \& Däuper, 2018; Schreyer et al., 2016, 2019).

\section{References}

Andreff, W., \& Scelles, N. (2015). Walter C. Neale 50 years after: Beyond competitive balance, the league standing effect tested With French football data. Journal of Sports Economics, 16(8), 819-834.

Angrist, J. D., \& Pischke, J.-S. (2009). Mostly harmless econometrics: An empiricist's companion. No. 8769 in Economics Books. Princeton University Press.

Benoit, M. (2008). The politicization of football: The European game and the approach to the Second World War. Soccer \& Society, 9(4), 532-550.

Bird, P. J. W. N. (1982). The demand for league football. Applied Economics, 14(6), 637-649.

Bond, A. J., \& Addesa, F. (2020). Competitive intensity, fans' expectations, and match-day tickets sold in the Italian football Serie A, 2012-2015. Journal of Sports Economics, 21(1), $20-43$.

Buraimo, B. (2008). Stadium attendance and television audience demand in English league football. Managerial and Decision Economics, 29(6), 513-523.

Buraimo, B., Tena, J. D., \& de la Piedra, J. D. (2018). Attendance demand in a developing football market: The case of the Peruvian first division. European Sport Management Quarterly, 18(5), 671-686.

Clowes, J., \& Clements, N. (2003). An exploration of discriminatory ticket pricing practice in the English football Premier League. Managing Leisure, 8(3), 105-120.

Cox, A. (2018). Spectator demand, uncertainty of results, and public interest: Evidence from the English Premier League. Journal of Sports Economics, 19(1), 3-30.

Dobson, S. M., \& Goddard, J. A. (1995). The demand for professional league football in England and Wales, 1925-92. Journal of the Royal Statistical Society. Series D (The Statistician), 44(2), 259-277.

Donald, S. G., \& Lang, K. (2007). Inference with difference-in-differences and other panel data. The Review of Economics and Statistics, 89(2), 221-233.

Elo, A. E. (1978). The rating of chessplayers, past and present. London: Batsford. 
Feehan, P., Forrest, D., \& Simmons, R. (2003). Premier league soccer: Normal or inferior good? European Sport Management Quarterly, 3(1), 31-45.

Forrest, D., \& Simmons, R. (2002). Outcome uncertainty and attendance demand in sport: The case of English soccer. Journal of the Royal Statistical Society: Series D (The Statistician), 51(2), 229-241.

Frevel, N., \& Schreyer, D. (2020). Behavioral responses to terrorist attacks: Empirical evidence from professional football. Applied Economics Letters, 27(3), 244-247.

Garcia, J., \& Rodríguez, P. (2002). The determinants of football match attendance revisited: Empirical evidence from the Spanish football league. Journal of Sports Economics, 3(1), $18-38$.

Gitter, S. (2017). The H1N1 virus and Mexican baseball attendance. Athens Journal of Sports, $4(4)$.

Giulianotti, R. (2012). Football. The Wiley-Blackwell Encyclopedia of Globalization.

Goller, D., \& Krumer, A. (2020). Let's meet as usual: Do games played on non-frequent days differ? Evidence from top European soccer leagues. European Journal of Operational Research, In press.

Gundlapalli, A. V., Rubin, M. A., Samore, M. H., Lopansri, B., Lahey, T., McGuire, H. L., Winthrop, K. L., Dunn, J. J., Willick, S. E., Vosters, R. L., et al. (2006). Influenza, Winter Olympiad, 2002. Emerging Infectious Diseases, 12(1), 144-146.

Hvattum, L. M., \& Arntzen, H. (2010). Using ELO ratings for match result prediction in association football. International Journal of Forecasting, 26(3), 460-470.

Kemper, C., \& Breuer, C. (2016). Dynamic ticket pricing and the impact of time - an analysis of price paths of the English soccer club Derby County. European Sport Management Quarterly, 16(2), 233-253.

Keogh-Brown, M. R., Wren-Lewis, S., Edmunds, W. J., Beutels, P., \& Smith, R. D. (2010). The possible macroeconomic impact on the UK of an influenza pandemic. Health Economics, 19(11), 1345-1360.

Kringstad, M., \& Gerrard, B. (2004). The concepts of competitive balance and uncertainty of outcome. In G. T. Papanikos (Ed.) The economics and management of mega athletic events: Olympic Games, professional sports and other essays. Athens, Greece: ATINER.

Kringstad, M., \& Gerrard, B. (2005). Theory and evidence on competitive intensity in European soccer. In Ottawa International Association of Sports Economists conference paper. Ottawa, Canada.

Kuo, H.-I., Chang, C.-L., Huang, B.-W., Chen, C.-C., \& McAleer, M. (2009). Estimating the impact of Avian Flu on international tourism demand using panel data. Tourism Economics, 15(3), 501-511. 
Page, S., Song, H., \& Wu, D. C. (2012). Assessing the impacts of the Global Economic Crisis and Swine Flu on inbound tourism demand in the United Kingdom. Journal of Travel Research, 51(2), 142-153.

Pawlowski, T., \& Anders, C. (2012). Stadium attendance in German professional football the (un)importance of uncertainty of outcome reconsidered. Applied Economics Letters, 19(16), 1553-1556.

Rassy, D., \& Smith, R. D. (2013). The economic impact of H1N1 on Mexico's tourist and pork sectors. Health Economics, 22(7), 824-834.

Reade, J. J., Schreyer, D., \& Singleton, C. (2020). Stadium attendance demand during the Covid-19 crisis: Early empirical evidence from Belarus. Available at SSRN 3651275.

Reuters (2020). Over half of people tested in Italy's Bergamo have COVID-19 antibodies. URL https: / / reut.rs/2YckFFm

Scelles, N., Durand, C., Bonnal, L., Goyeau, D., \& Andreff, W. (2016). Do all sporting prizes have a significant positive impact on attendance in a European national football league? Competitive intensity in the French Ligue 1. Ekonomicheskaya Politika/Economic Policy, 11(3), 82-107.

Schenkel, K., Williams, C., Eckmanns, T., Poggensee, G., Benzler, J., Josephsen, J., \& Krause, G. (2006). Enhanced surveillance of infectious diseases: The 2006 FIFA World Cup experience, Germany. Eurosurveillance, 11(12), 15-16.

Schreyer, D., \& Däuper, D. (2018). Determinants of spectator no-show behaviour: First empirical evidence from the German Bundesliga. Applied Economics Letters, 25(21), 1475-1480.

Schreyer, D., Schmidt, S. L., \& Torgler, B. (2016). Against all odds? Exploring the role of game outcome uncertainty in season ticket holders' stadium attendance demand. Journal of Economic Psychology, 56, 192 - 217.

Schreyer, D., Schmidt, S. L., \& Torgler, B. (2018). Predicting season ticket holder loyalty using geographical information. Applied Economics Letters, 25(4), 272-277.

Schreyer, D., Schmidt, S. L., \& Torgler, B. (2019). Football spectator no-show behavior. Journal of Sports Economics, 20(4), 580-602.

Shapiro, S. L., \& Drayer, J. (2012). A new age of demand-based pricing: An examination of dynamic ticket pricing and secondary market prices in Major League Baseball. Journal of Sport Management, 26(6), 532-546.

Shapiro, S. L., \& Drayer, J. (2014). An examination of dynamic ticket pricing and secondary market price determinants in Major League Baseball. Sport Management Review, 17(2), $145-159$.

Simmons, R. (1996). The demand for English League Football: A club-level analysis. Applied Economics, 28(2), 139-155. 
Simmons, R., \& Forrest, D. (2006). New issues in attendance demand: The case of the English Football League. Journal of Sports Economics, 7(3), 247-263.

Soebbing, B. P. (2019). Ticket Pricing. In P. Downward, B. Frick, B. R. Humphreys, T. Pawlowski, J. E. Ruseski, \& B. P. Soebbing (Eds.) The SAGE Handbook of Sports Economics. California, United States: SAGE Publishing.

Stoecker, C., Sanders, N. J., \& Barreca, A. (2016). Success is something to sneeze at: Influenza mortality in cities that participate in the Super Bowl. American Journal of Health Economics, 2(1), 125-143.

Szymanski, S. (2020). Covid-19 and football club insolvency. Mimeo.

Valenti, M., Scelles, N., \& Morrow, S. (2020). The determinants of stadium attendance in elite women's football: Evidence from the uefa women's champions league. Sport Management Review, 23(3), 509-520.

Verdoni, L., Mazza, A., Gervasoni, A., Martelli, L., Ruggeri, M., Ciuffreda, M., Bonanomi, E., \& D'Antiga, L. (2020). An outbreak of severe Kawasaki-like disease at the Italian epicentre of the SARS-CoV-2 epidemic: an observational cohort study. The Lancet, 395(10239), 1771-1778.

Woolridge, J. (2002). Mapping the stars: Stardom in English professional football 1890-1946. Soccer \& Society, 3(2), 51-69. 
TABLE 1: Summary statistics over football matches, 2015/16-2019/20

\begin{tabular}{|c|c|c|c|c|c|}
\hline & Mean & St. Dev. & Min. & Median & Max. \\
\hline \multicolumn{6}{|l|}{ English Premier League } \\
\hline Attendance (1000s) & 37.5 & 16.4 & 10.0 & 32.0 & 83.2 \\
\hline Home Elo rating & 1153 & 124 & 855 & 1129 & 1548 \\
\hline Away Elo rating & 1147 & 121 & 871 & 1119 & 1552 \\
\hline$N$ of (home) teams & & & 29 & & \\
\hline$N$ of home-away team pairs & & & 709 & & \\
\hline$N$ of matches & & & 1,808 & & \\
\hline \multicolumn{6}{|l|}{ French Ligue 1} \\
\hline Attendance (1000s) & 22.0 & 12.8 & 1.1 & 17.6 & 65.4 \\
\hline Home Elo rating & 1115 & 109 & 847 & 1102 & 1465 \\
\hline Away Elo rating & 1110 & 106 & 858 & 1090 & 1436 \\
\hline$N$ of (home) teams & & & 27 & & \\
\hline$N$ of home-away team pairs & & & 642 & & \\
\hline$N$ of matches & & & 1,791 & & \\
\hline \multicolumn{6}{|l|}{ German Bundesliga } \\
\hline Attendance (1000s) & 42.9 & 17.7 & 13.2 & 41.5 & 81.4 \\
\hline Home Elo rating & 1087 & 105 & 867 & 1075 & 1432 \\
\hline Away Elo rating & 1083 & 103 & 824 & 1068 & 1400 \\
\hline$N$ of (home) teams & & & 24 & & \\
\hline$N$ of home-away team pairs & & & 496 & & \\
\hline$N$ of matches & & & 1,447 & & \\
\hline \multicolumn{6}{|l|}{ Italian Serie A } \\
\hline Attendance (1000s) & 24.2 & 14.2 & 0.5 & 19.8 & 79.2 \\
\hline Home Elo rating & 1140 & 125 & 829 & 1114 & 1498 \\
\hline Away Elo rating & 1138 & 126 & 857 & 1110 & 1470 \\
\hline$N$ of (home) teams & & & 28 & & \\
\hline$N$ of home-away team pairs & & & 661 & & \\
\hline$N$ of matches & & & 1,768 & & \\
\hline \multicolumn{6}{|l|}{ Spanish La Liga } \\
\hline Attendance (1000s) & 27.6 & 19.3 & 3.3 & 19.9 & 99.2 \\
\hline Home Elo rating & 1143 & 119 & 897 & 1123 & 1471 \\
\hline Away Elo rating & 1142 & 121 & 896 & 1119 & 1476 \\
\hline$N$ of (home) teams & & & 27 & & \\
\hline$N$ of home-away team pairs & & & 648 & & \\
\hline$N$ of matches & & & 1,787 & & \\
\hline
\end{tabular}

Notes.- statistics are calculated over all matches in the top domestic leagues of England, France, Germany, Italy, and Spain since the beginning of the 2015/16 season. Excludes matches with no spectators, i.e., played 'behind closed doors'. Source.- worldfootball.net; accessed 14 March 2020. 


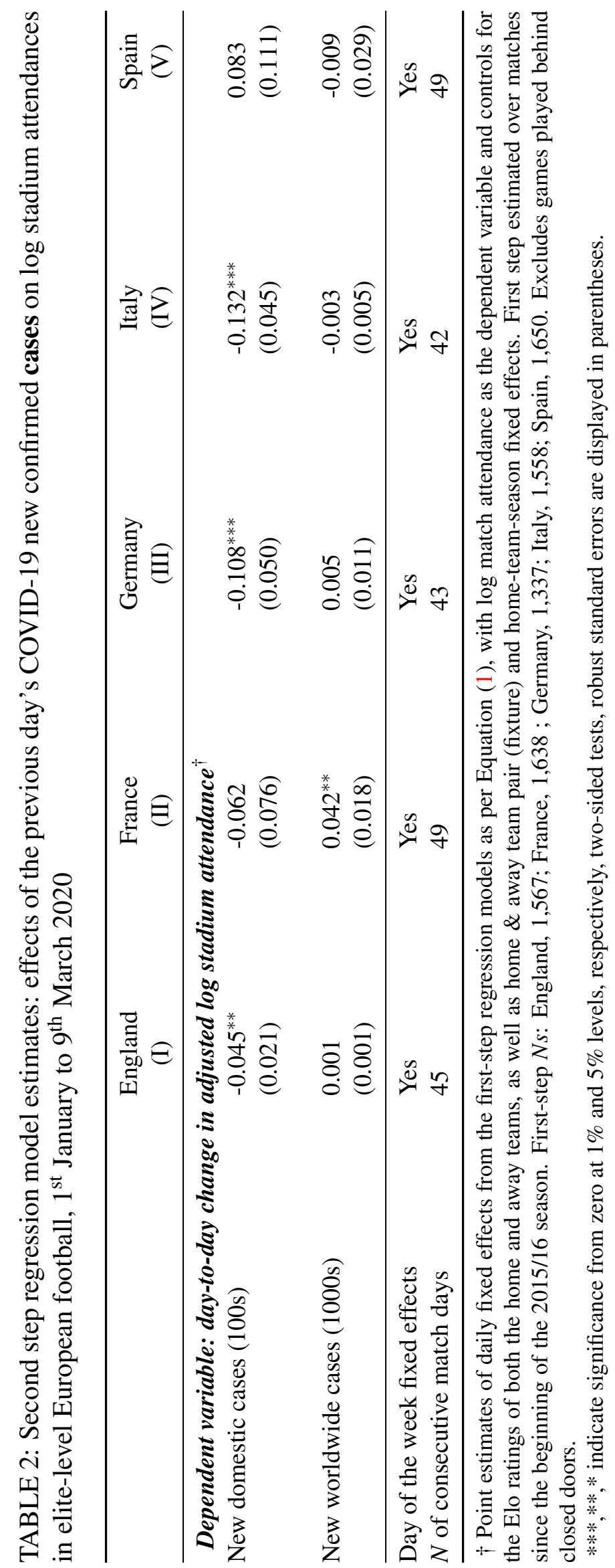




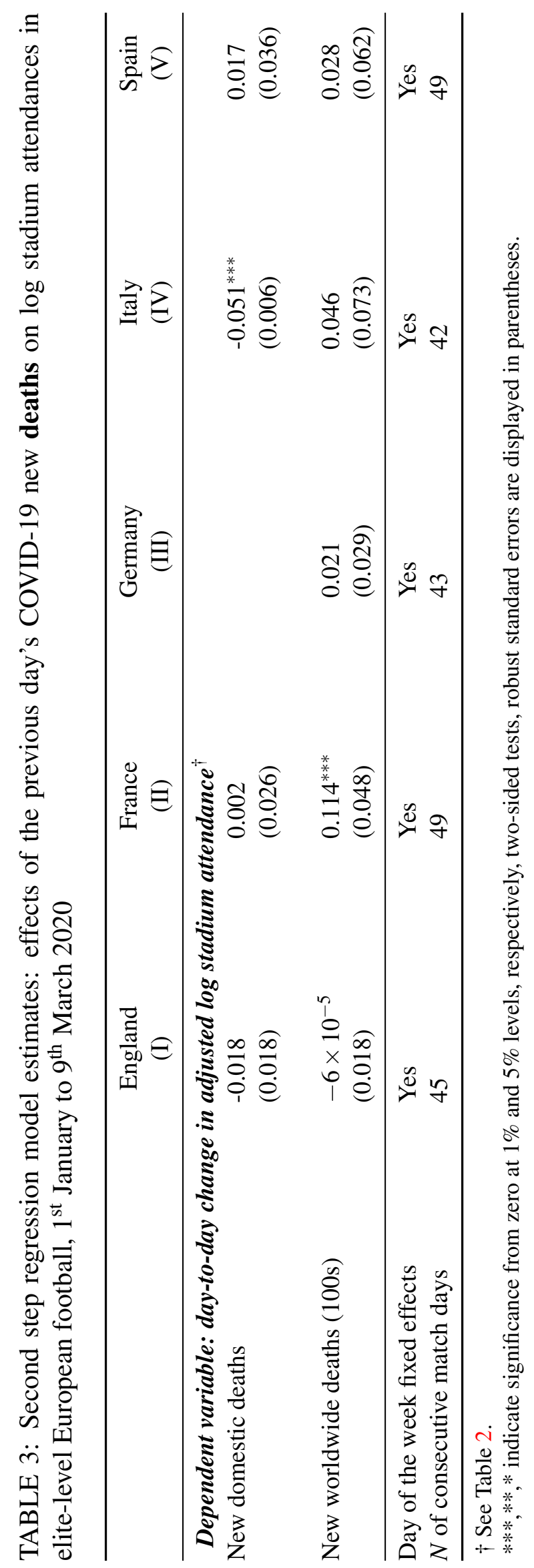


FIGURE 1: Total numbers of confirmed cases and deaths from COVID-19, January to April 2020
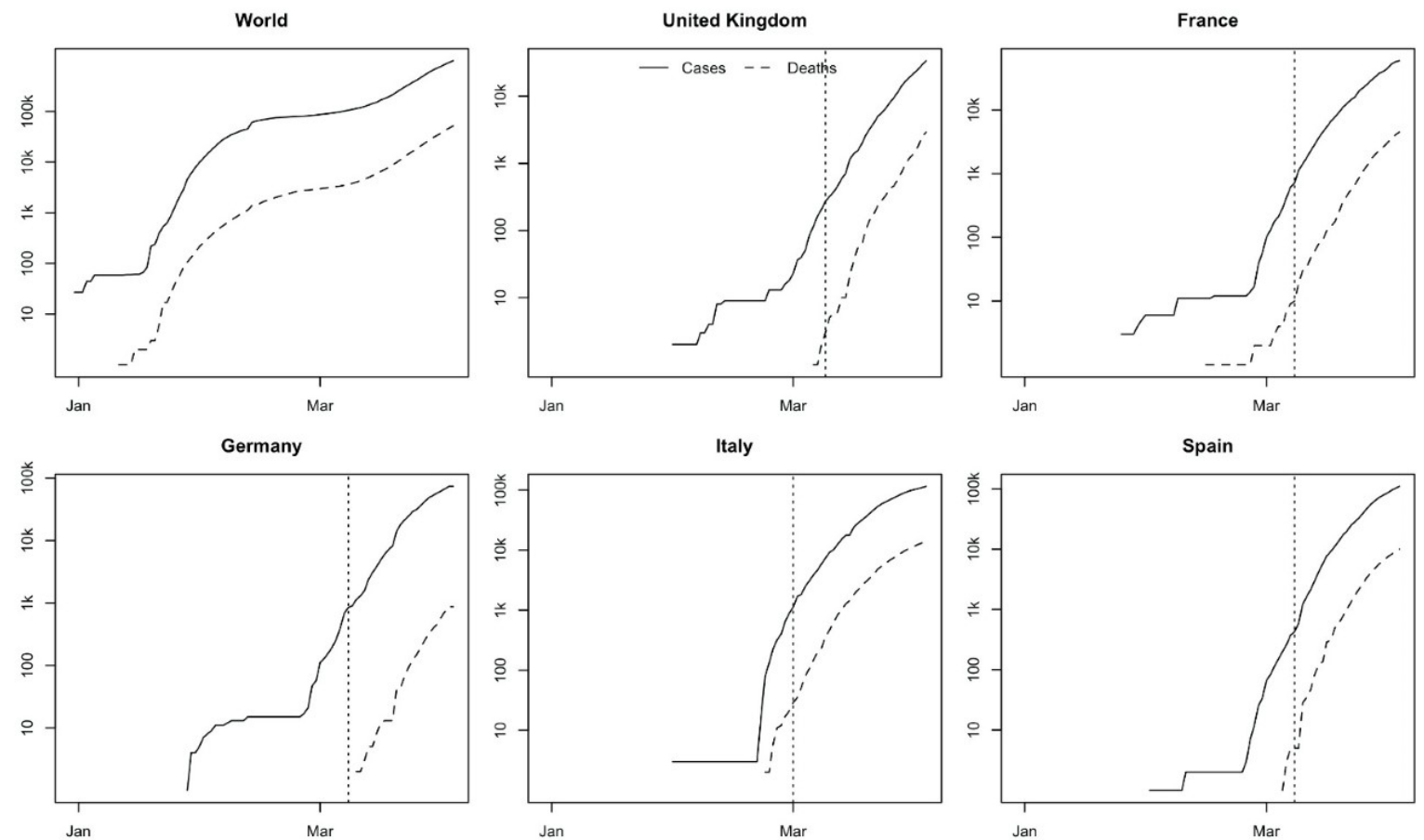

Source.- ourworldindata.org/coronavirus-source-data; accessed 3 April 2020, vertical dashed lines denote the final football match played in front of spectators in the top league of each respective country ( $1^{\text {st }}$ March in Italy, $8^{\text {th }}$ March in France, Germany and Spain and $9^{\text {th }}$ March in England). 
FIGURE 2: Adjusted average daily attendances in top football leagues, February to March 2020
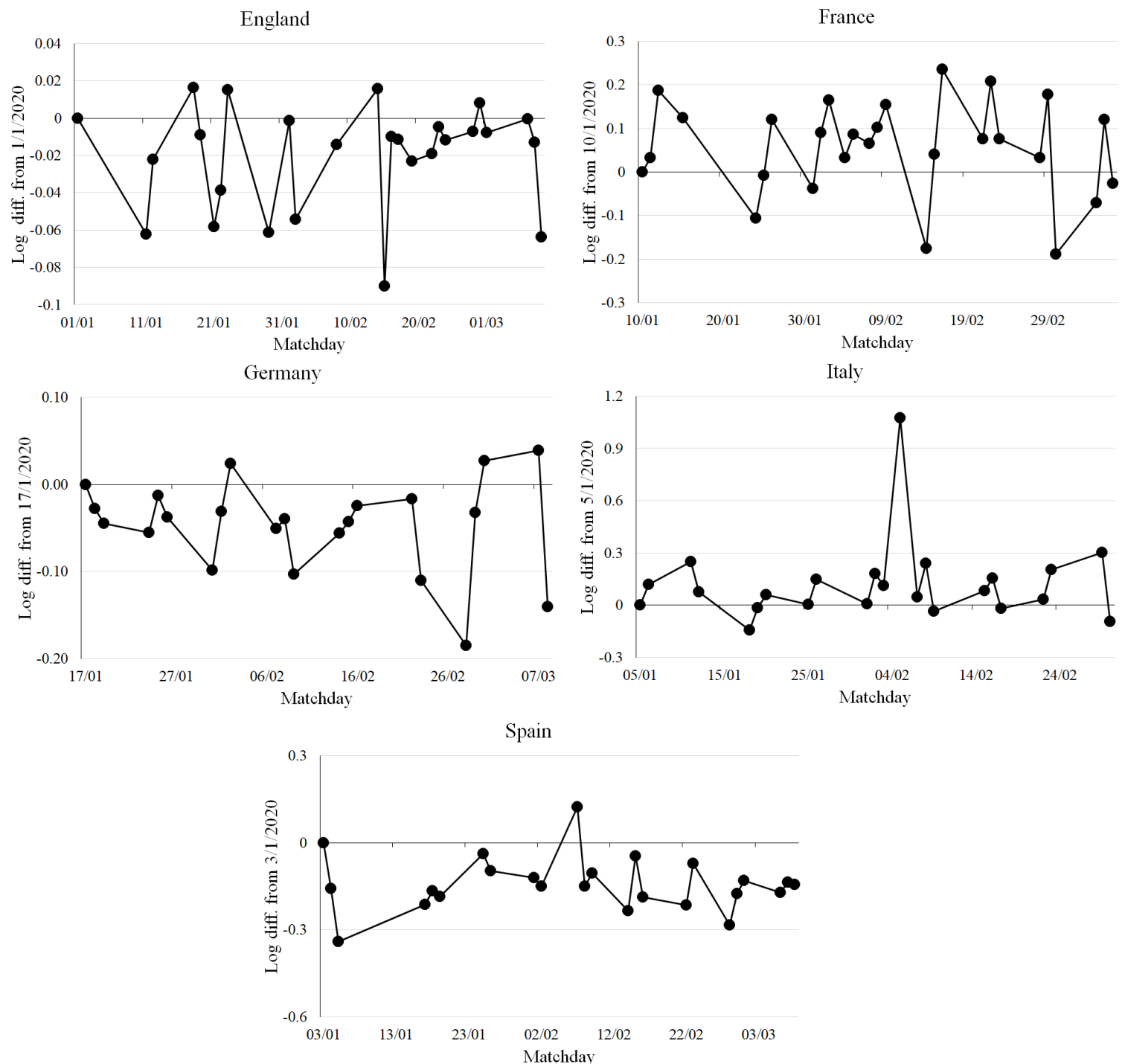

Source.- author calculations using data from worldfootball.net. Figures give the point estimates of $\widehat{d_{t}}$ from the first-step regression of Equation (1). Interpretation: the log difference in adjusted daily match-day attendances from the first date shown. 